\title{
Commentary: Chronic type A dissection: When to operate?
}

\author{
Francois Dagenais, MD
}

\footnotetext{
From the Department of Cardiac Surgery, Institut Universitaire de Cardiology et Pneumologie de Québec, Québec, Québec, Canada.

Disclosures: Author has nothing to disclose with regard to commercial support.

Received for publication Nov 4, 2018; accepted for publication Nov 5, 2018; available ahead of print Dec 11, 2018.

Address for reprints: Francois Dagenais, MD, Department of Cardiac Surgery, Institut Universitaire de Cardiology et Pneumologie de Québec, 2725 chemin Sainte-Foy, Québec, Québec, Canada G1V4G5 (E-mail: francois. dagenais@chg.ulaval.ca).

J Thorac Cardiovasc Surg 2019;158:1005-6

$0022-5223 / \$ 36.00$

Copyright (c) 2018 by The American Association for Thoracic Surgery

https://doi.org/10.1016/j.jtcvs.2018.11.032
}

Current guidelines for surgery in patients with chronic type A dissection base the operative indication on the natural history of aneurysmal degeneration of the ascending aorta, thus an aortic diameter of greater than $5.5 \mathrm{~cm}$. Data to support this recommendation are limited to a few small studies. ${ }^{1,2}$ In the current issue of the Journal, Kim and colleagues ${ }^{3}$ report an interesting study of 142 patients with chronic type A dissection treated during an 18-year period. A total of 60 patients underwent operation up-front, but nonoperative treatment was decided in 82 patients, among whom $74(90.2 \%)$ were followed for a mean of 6.4 years. Adverse aortic events occurred in 19 of these patients (3.5\%/patient-year), and an additional 6 patients (1.13\%/patient-year) underwent elective operation during the follow-up period. Risk of aortic-related events at 5 years was estimated at $13.3 \%, 14.9 \%$, and $16.8 \%$ for aortic diameters of 50 , 55 , and $60 \mathrm{~mm}$, respectively. Older age, a larger baseline aortic diameter, presence of hypertension, and annual growth rate were identified as predictors of aortic adverse events.

These interesting data suggest a worse prognosis of chronic type A dissection compared with nondissecting aneurysms of the ascending aorta. The authors rightfully conclude that operative indication should be reviewed at a lower aortic diameter threshold than for nondissection aneurysms. Further in-depth analysis of the article allows to better define which subset of patients may benefit from an earlier operation. Because of a decrease in the estimated risk of aortic rupture with time, chronic type A dissection is defined by the diagnosis of an intimal flap in the ascending aorta after 14 days of the initial symptoms. However, the risk of rupture, although lower than the initial 2 weeks, is still significant within the 4 to 6 weeks after the initial aortic tear. Thus, a patient with a

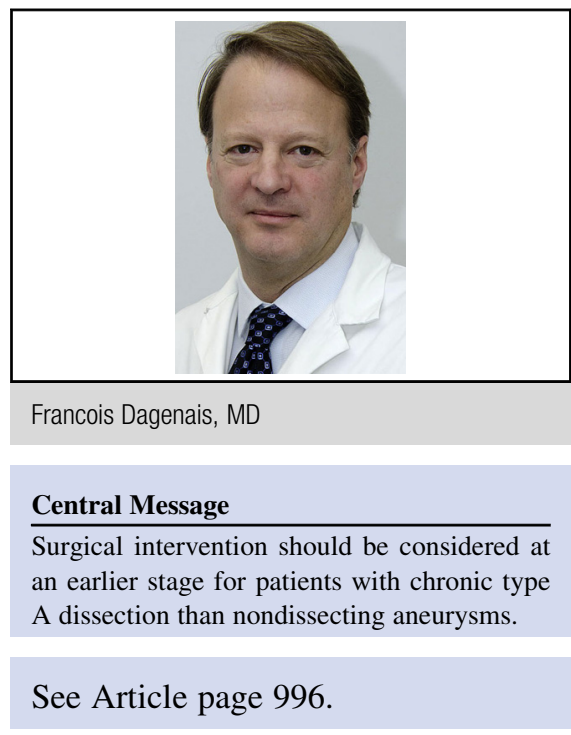

recent (within 4-6 weeks) history of chest pain should be considered at higher risk of aortic rupture and operated at a lower aortic diameter threshold. Data of the present study supporting advanced age as a predictor of adverse aortic event may be misleading. One should be cautioned to recommend a more conservative approach in the younger age group. Sudden unexplained death due to an unrelated aortic cause may be more frequent in the elderly population and account for a higher total adverse-related event rate in the elderly. Accordingly, 7 of 9 patients $(77.8 \%)$ died suddenly without an identifiable cause in the group aged more than 70 years compared with 4 of 10 patients $(40 \%)$ aged less than 70 years. Furthermore, as well stated by the authors, the cumulative risk of adverse aortic events with time in a young patient supports an early operative approach in the young patients with chronic type A dissection. DeBakey type also should be assessed in the decision of when to operate. Within the present study, 10 of 82 patients $(12.2 \%)$ treated medically presented a chronic type II DeBakey dissection compared with 33 of 60 patients $(55 \%)$ with up-front surgery. The complete removal of the dissected tissue in patients with type II dissection portends a significantly better prognosis and should prompt an earlier surgical intervention. The extent of aortic resection in patients with type I chronic aortic dissection is debatable because aortic rupture distal to the ascending aorta may supervene, as observed in 1 patient in the present study. Extending the resection to a full arch with or without 
a frozen elephant trunk resection may be considered in young, low-risk patients with moderate dilatation of the arch/descending aorta.

The study by Kim and colleagues ${ }^{3}$ sheds new light on the natural history of chronic type A dissection. Surgical intervention should be considered at an earlier stage than nondissecting aneurysms. Further studies may allow to better delineate at which aortic threshold less than $55 \mathrm{~mm}$ surgery should be recommended. However, an early interval $(<4-6$ weeks) between the diagnosis and intimal tear, and presence of a DeBakey type II dissection, especially in young patients with good life expectancy, should dictate an early surgical intervention at a diameter less than $55 \mathrm{~mm}$.

\section{References}

1. Elefteriades JA. Natural history of thoracic aortic aneurysms: indications for surgery, and surgical versus nonsurgical risks. Ann Thorac Surg. 2002;74:S1877-80; discussion S1892-8.

2. Erbel R, Aboyans V, Boileau C, Bossone E, Bartolomeo RD, Eggebrecht H, et al. 2014 ESC guidelines on the diagnosis and treatment of aortic diseases: document covering acute and chronic aortic diseases of the thoracic and abdominal aorta of the adult. The task force for the diagnosis and treatment of aortic diseases of the European Society of Cardiology (ESC). Eur Heart J. 2014;35:2873-926.

3. Kim WK, Park SJ, Kim HJ, Kim HJ, Choo SJ, Kim JB. The fate of unrepaired chronic type A aortic dissection. J Thorac Cardiovasc Surg. 2019;158:996-1004.e3. 